\title{
Arthroscopic iliac crest bone grafting in recurrent anterior shoulder instability: minimum 5-year clinical and radiologic follow-up
}

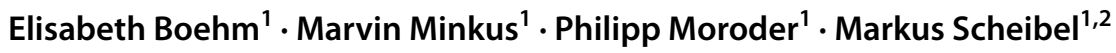

Received: 23 November 2019 / Accepted: 7 April 2020 / Published online: 13 April 2020

(c) The Author(s) 2020

\begin{abstract}
Purpose To investigate the clinical and radiologic mid- to long-term results of arthroscopic iliac crest bone-grafting for anatomic glenoid reconstruction in patients with recurrent anterior shoulder instability.

Methods Seventeen patients were evaluated after a minimum follow-up of 5 years. Clinical [range of motion, subscapularis tests, apprehension sign, Subjective Shoulder Value (SSV), Constant Score (CS), Rowe Score (RS), Walch Duplay Score (WD), Western Ontario Shoulder Instability Index (WOSI)], and radiologic [X-ray (true a.p., Bernageau and axillary views) and computed tomography (CT)] outcome parameters were assessed.

Results Fourteen patients [mean age 31.1 (range 18-50) years] were available after a follow-up period of 78.7 (range 60-110) months. The SSV averaged 87 (range 65-100) \%, CS 94 (range 83-100) points, RS 89 (range 30-100) points, WD 87 (range 25-100) points, and WOSI 70 (range 47-87) \%. The apprehension sign was positive in two patients (14\%). One patient required an arthroscopic capsular plication due to a persisting feeling of instability, while the second patient experienced recurrent dislocations after a trauma, but refused revision surgery. CT imaging showed a significant increase of the glenoid index from preoperative $0.8 \pm 0.04$ (range $0.7-0.8$ ) to $1.0 \pm 0.11$ (range $0.8-1.2$ ) at the final follow-up $(p<0.01$ ).

Conclusion Arthroscopic reconstruction of anteroinferior glenoid defects using an autologous iliac crest bone-grafting technique yields satisfying clinical and radiologic results after a mid- to long-term follow-up period. Postoperative re-dislocation was experienced in one $(7.1 \%)$ of the patients due to a trauma and an anatomic reconstruction of the pear-shaped glenoid configuration was observed.
\end{abstract}

Level of evidence IV.

Keywords Shoulder instability Glenoid defect $\cdot$ Autograft $\cdot$ Autologous iliac crest bone grafting $\cdot$ Anatomic glenoid reconstruction $\cdot$ Bone block procedure

\section{Introduction}

Bony glenoid defects frequently occur in patients with recurrent anterior shoulder instability, and numerous surgical techniques have been described to restore the pear-shaped

Elisabeth Boehm and Marvin Minkus have equally contributed to the conduction of this work.

Markus Scheibel

Markus.Scheibel@charite.de

1 Department of Shoulder and Elbow Surgery, Center for Musculoskeletal Surgery, Charité-Universitätsmedizin Berlin, Augustenburger Platz 1, 13353 Berlin, Germany

2 Department of Shoulder and Elbow Surgery, Schulthess Clinic Zurich, Zurich, Switzerland anatomy and concavity of the glenoid [8, 20, 45]. In general, free bone block procedures can be differentiated from the coracoid transfer. While the stabilizing effect of the nonanatomic Latarjet procedure is generated by the bone block acting as a mechanic barrier in combination with a sling effect of the conjoined tendons, free bone block procedures aim to restore the glenoid concavity and anatomy of the glenohumeral joint to re-establish stability $[4,19,25,30,47$, 52-54]. A variety of open bone-grafting techniques with different graft fixation methods and bone harvesting sites have been published and yield satisfying clinical and radiological outcomes in the long term $[4,12,29]$. However, the structural integrity and clinical function of the subscapularis tendon may be compromised after open shoulder stabilization procedures [36, 42]. Due to advancements of arthroscopic techniques and instruments, all-arthroscopic bone-grafting 
procedures for glenoid reconstruction are performed for several years now. In 2008, we published an arthroscopic autologous iliac crest bone-grafting technique [37]. Results after a short-term follow-up period of our own patient series were reported in 2014, which showed successful reconstruction of the pear-shaped glenoid anatomy as well as excellent early clinical outcomes [24]. Other authors observed similar results following arthroscopic bone-grafting techniques after a short-term follow-up period [2, 18]. However, clinical and radiologic mid- to long-term data of arthroscopic iliac crest bone grafting are presently deficient.

The aim of this study was to evaluate the clinical and radiologic mid- to long-term results of anatomic glenoid reconstruction using an all-arthroscopic, autologous tricortical iliac crest bone-grafting technique in patients with recurrent anterior shoulder instability. The hypothesis was that patients show good clinical results and a stable shoulder joint with an anatomic glenoid configuration after a minimum follow-up period of 5 years.

\section{Materials and methods}

Approval to perform this study was granted by the local ethical committee (Charite-Universitaetsmedizin Berlin, EA4/168/15). Patients with recurrent anteroinferior glenohumeral shoulder instability and substantial osseous defects of the glenoid rim that underwent arthroscopic anatomic glenoid reconstruction using an autologous iliac crest bone graft between 2007, when we introduced this procedure in our department, until 2012 were identified, and evaluated over a mid- to long-term follow-up period. Cases of chronic fragment-type lesions (type II) or a chronic erosiontype lesions without a bony fragment and a defect size of either $<25 \%$ (type IIIa) or $\geq 25 \%$ (type IIIb) of the glenoid surface area according to Scheibel et al. [38] were enrolled. Exclusion criteria were fractures of adjacent osseous structures including the clavicle and coracoid process as well as shoulder stiffness and a follow-up-period of less than 5 years.

\section{Patient population}

17 patients were identified meeting the inclusion and exclusion criteria. After a minimum follow-up of 5 years, 14 patients [ 1 female/13 male, mean age 31.1 (range 18-50) years] were available for re-evaluation, corresponding to a follow-up rate of $82.4 \%$. Three patients were not available for follow-up examination, as their contact information changed without notice. The mean follow-up period was 78.7 (range 60-110) months. All patients were operated by the senior author. Baseline characteristics of the patients are listed in Table 1.
Table 1 Baseline characteristic of the patients available for follow-up and grade of instability arthropathy (IA) at baseline and follow-up

\begin{tabular}{ll}
\hline Number of patients & 14 \\
Female & 1 \\
Male & 13 \\
Mean age at surgery (years) & 31.1 \\
Dominant side affected & 6 \\
Number of prior surgeries & \\
0 & 5 \\
1 & 4 \\
2 & 3 \\
3 & 1 \\
4 & 1 \\
Glenoid defect type ${ }^{\mathrm{a}}$ & \\
II & 7 \\
IIIA & 1 \\
IIIB & 6 \\
Preoperative IA grade & \\
0 & \\
I & \\
II & 9 \\
Follow-up IA grade & \\
0 & 4 \\
I & 1 \\
II & \\
\hline
\end{tabular}

${ }^{\text {a }}$ Classification according to Scheibel et al. [38]

${ }^{\mathrm{b}}$ Classification according to Samilson and Prieto [35]

\section{Surgical technique}

The autologous iliac crest bone-grafting technique was performed arthroscopically as described in the original publication by Scheibel et al. [24, 37]. Therefore, the following description of the surgical procedure is restricted to a summary of the essential surgical steps.

The patient is placed in the lateral decubitus position with the affected arm fixed in a traction device and the ipsilateral iliac crest prepared in a sterile fashion. Four portals are required for this all-arthroscopic approach including a standard posterior, an anterosuperior, an anteroinferior, and a transtendinous deep anteroinferior portal. First, the capsule-labrum complex is mobilized and the scapular neck is prepared for the graft placement (Fig. 1a). In the case of a fragment-type lesion (type II), smaller fragments should be resected, while larger fragments can either later be re-attached together with the capsule-labrum complex or left in place if they are located in a medial position to act as additional support to the bone graft. According to the dimensions of the glenoid defect, a tricortical autologous bone graft measuring 
Fig. 1 Arthroscopic iliac crest bone-grafting surgical technique in the case of a type II fragment-type glenoid lesion. a Visualization of the glenoid defect after mobilization of the capsule-labrum complex and preparation of the scapular neck. b Arthroscopic view of the anatomic glenoid reconstruction including refixation of the capsule-labrum complex
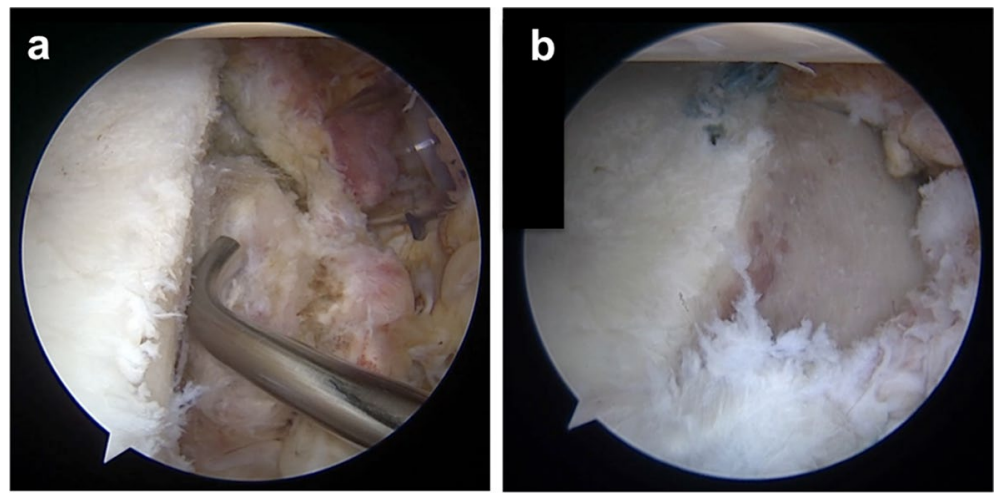

$2.5-3 \mathrm{~cm} \times 1-1.5 \mathrm{~cm} \times 1-1.5 \mathrm{~cm}$ is harvested from the ipsilateral iliac crest, inserted into the glenohumeral joint through the anteroinferior portal and positioned anatomically. The bone block is fixed to the scapular neck using a special drill guide (Twist-Drill Guide; Arthrex, Naples, Florida) that contains a drill sleeve as well as a K-wire placement sleeve and is inserted through the deep anteroinferior portal. The graft is thereby temporarily stabilized in the anatomic position via $\mathrm{K}$-wires followed by its definite fixation to the scapular neck using two $26 \mathrm{~mm}$ Bio-Compression screws with a diameter of 3 or $3.7 \mathrm{~mm}$ depending on the graft size (Arthrex, Naples, Florida). Finally, the capsule-labrum complex is re-attached using two knotless $2.9 \times 15.5 \mathrm{~mm}$ PushLock anchors (Arthrex, Naples, Florida) to complete the anatomic glenoid reconstruction (Fig. 1b).

\section{Postoperative treatment and rehabilitation}

Postoperatively, the shoulder is immobilized in a sling in internal rotation for 6 weeks and only a limited passive range-of-motion up to $90^{\circ}$ of flexion and $20^{\circ}$ of external rotation in adduction is allowed. Active range-of-motion exercises are initiated 7 weeks postoperatively followed by muscle strengthening after 10-12 weeks.

\section{Clinical evaluation}

Two investigators (E.B. and M.M.) who were not involved during the surgical intervention performed the final follow-up examination of both shoulders. Any postoperative events of instability including a subjective feeling of instability, subluxations, and dislocations were documented and explored. Clinical evaluation comprised the active range of flexion, abduction, glenohumeral abduction, and external and internal rotation in adduction as well as in $90^{\circ}$ of abduction in comparison to the contralateral side. The apprehension sign [34] as well as specific subscapularis tests including the belly-press test [16], belly-off sign [39], lift-off test [17], and internal rotation lag sign [21] were evaluated. The Subjective Shoulder Value (SSV), Constant Score (CS), Rowe Score (RS), Walch Duplay Score (WD), and the Western Ontario Shoulder Instability Index (WOSI) were recorded for assessment of the subjective and objective shoulder function and glenohumeral stability. Glenohumeral strength of both shoulders was measured with the arm positioned in $90^{\circ}$ of abduction in the scapular plane using an isometric dynamometer (Isobex TM dynamometer, Medical Device Solutions AG, Burgdorf, Switzerland).

\section{Radiologic evaluation}

At the final follow-up, unilateral true anteroposterior and axillary view radiographic images of the affected side as well as bilateral Bernageau views of both shoulders were used to evaluate the presence and progression of instability arthropathy according to the Samilson and Prieto classification [35] in comparison to preoperative radiographic images. Computed tomography (CT) images of both shoulders with three-dimensional (3D) reconstruction of the glenoid and subtraction of the humeral head were conducted at the final follow-up and compared to preoperative and directly postoperative images and corresponding radiologic measurements. The glenoid index (GI) was calculated on the basis of the ratio of the glenoid width (GW) and glenoid length (GL) in comparison to the values of the contralateral glenoid according to Chuang et al. [11]. Furthermore, the glenoid surface area (GA) of the affected as well as the non-affected glenoid was measured. The presence of osteolytic lesions associated with the Bio-Compression screws was assessed on twodimensional (2D) CT images and the grade of osteolysis was analyzed descriptively.

\section{Statistical analysis}

Statistical analysis was conducted using SPPS Statistics Version 23.0 (IBM, Armonk, NY, USA). For descriptive statistics, the mean and standard deviation are demonstrated. The results were tested for normal distribution employing the Kolmogorov-Smirnov Test. To compare the means, the 
$T$ Test was used for paired samples of parametric data, the Wilcoxon Test for paired samples of non-parametric data, and the Mann-Whitney- $U$-Test for unpaired samples. For all analyses, the level of significance was defined as $p<0.05$.

\section{Results}

\section{Clinical results}

The mean active range-of-motion at follow-up was comparable to the contralateral side in forward flexion, abduction, glenohumeral abduction, and internal rotation at $90^{\circ}$ ( $p$ values not significant (n.s.)). A significant difference of the range-of-motion compared to the contralateral side was observed in external rotation in the neutral position as well as in $90^{\circ}$ of abduction ( $p=0.027$ and $p=0.037$ ) (Table 2).

The apprehension sign was positive in two patients (14\%). One of these patients experienced a traumatic re-dislocation postoperatively followed by five additional recurrent dislocations at the point of the final follow-up. Further information on this case is provided in the complications section. Twelve patients $(86 \%)$ showed a completely stable shoulder joint with a negative apprehension sign and no events of recurrent instability. The specific subscapularis tests were negative in all patients and no clinical signs for subscapularis insufficiency were observed. The strength in abduction in the scapular plane was comparable ( $p$ value n.s.) on the affected side $(11.0 \pm 3.0 \mathrm{~kg})$ and contralateral side $(11.8 \pm 3.8 \mathrm{~kg})$. The subjective and objective clinical outcome parameters of the follow-up evaluation are displayed in Table 3. The patient who experienced recurrent dislocations showed predictably unsatisfying clinical results.

\section{Radiologic results}

In 6 patients, no signs of instability arthropathy were detected. 5 patients showed a grade I and 3 patients a grade II instability arthropathy. In 4 patients, a pre-existing

Table 2 Active range-of-motion at the follow-up evaluation

\begin{tabular}{lcll}
\hline & Affected side & Contralateral side & $p$ value \\
\hline Flexion, deg & $177 \pm 4.7$ & $179 \pm 4.9$ & $n . s$ \\
Abduction, deg & $175 \pm 7.9$ & $178 \pm 4.8$ & $n . s$ \\
Glenohumeral abduction, & $90 \pm 1.3$ & $90 \pm 1.4$ & $n . s$ \\
$\quad$ deg & & & \\
External rotation, deg & $58 \pm 16.7$ & $72 \pm 13.3$ & 0.027 \\
$\begin{array}{l}\text { External rotation at } 90^{\circ}, \\
\quad \text { deg }\end{array}$ & $75 \pm 19.1$ & $88 \pm 8.3$ & 0.037 \\
$\begin{array}{l}\text { Internal rotation at } 90^{\circ}, \\
\quad \text { deg }\end{array}$ & $71 \pm 14.1$ & $75 \pm 11.9$ & $n . s$ \\
\hline
\end{tabular}

n.s. not significant
Table 3 Clinical outcome parameter at the follow-up evaluation

\begin{tabular}{llll}
\hline & Mean \pm SD & Minimum & Maximum \\
\hline Constant Score, pts & $94 \pm 4.9$ & 83 & 100 \\
Rowe Score, pts & $89 \pm 18.4$ & 30 & 100 \\
Walch-Duplay Score, pts & $87 \pm 10$ & 25 & 100 \\
WOSI, \% & $70 \pm 13.8$ & 47 & 87 \\
SSV, \% & $87 \pm 10$ & 65 & 100 \\
\hline
\end{tabular}

WOSI Western Ontario Shoulder Instability Index, SSV Subjective Shoulder Value

osteoarthritis ( $n=3$ grade I, $n=1$ grade II) showed no signs of progression during the follow-up period (Table 1).

CT imaging at follow-up showed a consolidated autologous iliac crest bone graft in all cases. Preoperative CT scans showed a mean glenoid area of $728.2 \pm 108.8 \mathrm{~mm}^{2}$ on the affected side and $799.1 \pm 107.6 \mathrm{~mm}^{2}$ on the contralateral side. In all patients, a postoperative CT scan was performed to confirm correct positioning of the graft. No malpositioning became evident. The glenoid area was initially overcorrected to $982 \pm 158.2 \mathrm{~mm}^{2}$ directly postoperatively. At the final follow-up examination, the surface area of the glenoid was $822.6 \pm 136.4 \mathrm{~mm}^{2}$ (Figs. 2, 3). A remodeling process of the initially over-constructed glenoid surface towards the pear-shaped anatomic glenoid configuration was observed over the follow-up period (Fig. 2). At the final follow-up, this anatomic shape was maintained similar to the contralateral side. The glenoid index (GI) showed a significant increase from preoperative $0.8 \pm 0.04$ (range $0.7-0.8$ ) to $1.1 \pm 0.06$ (range 1.0-1.2) immediately postoperative in terms of an overcorrection $(p<0.01)$. Due to the glenoid remodeling process, the GI normalized to a value of $1.0 \pm 0.11$ (range $0.8-1.2$ ) at the latest follow-up (Fig. 4), which is equal to a significant increase compared to the preoperative value $(p<0.01)$.

No severe osteolytic lesions were present in any of the patients. In all cases, the former position of the screws was identifiable on the final CT scans. Mild osteolytic lesions were visible at the insertion site of the former screws in nine patients (64.3\%), which showed no progression over time. However, the impact or clinical relevance of these observations remains uncertain. In the patient who experienced a traumatic recurrent dislocation, a fracture of the graft along an osteolytic line can be assumed (Fig. 5).

\section{Complications}

One patient reported a temporary hypaesthesia at the harvesting site of the iliac crest following the surgery, which fully regressed over time. Another patient complained of a persistent subjective feeling of shoulder instability without events of recurrent dislocations and was treated with a 

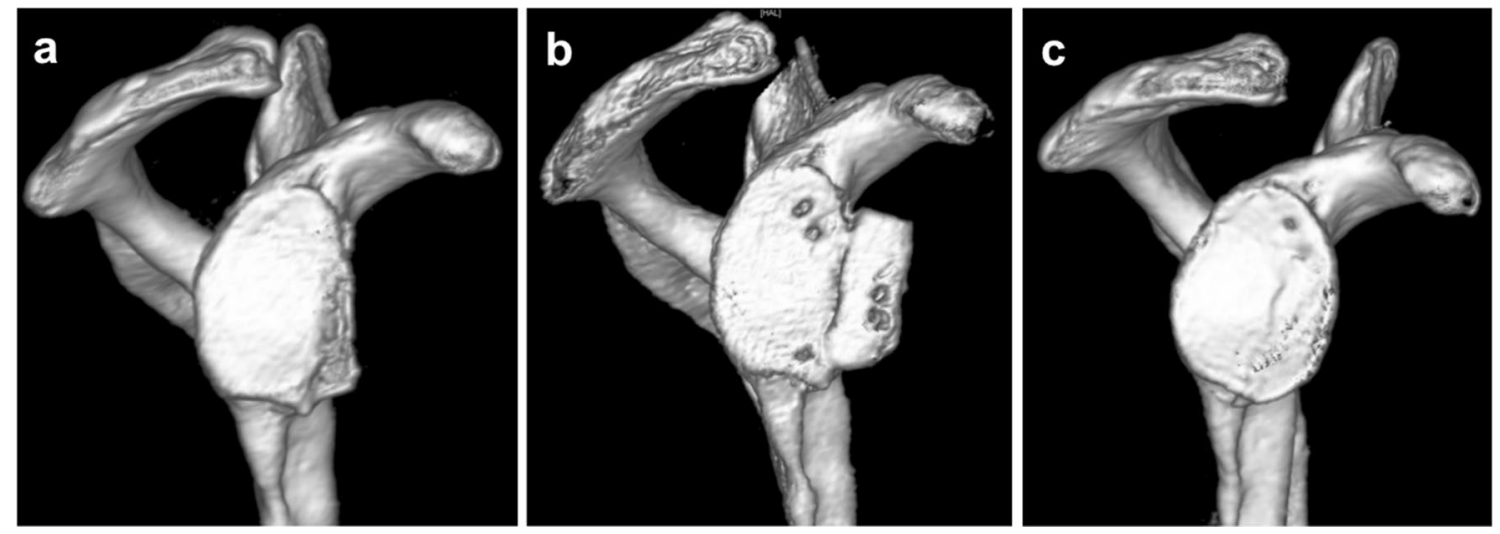

Fig. 2 3D-CT-reconstruction of the scapula with subtraction of the humeral head (a) preoperative, (b) directly postoperative, and (c) at the final follow-up 78.7 months postoperatively displaying the remodeling process of the glenoid

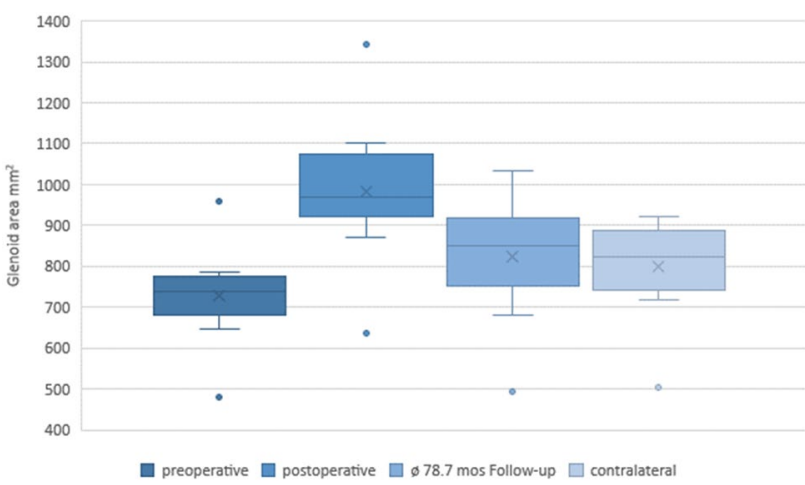

Fig. 3 Glenoid area preoperative, immediately postoperative, and at the final follow-up examination

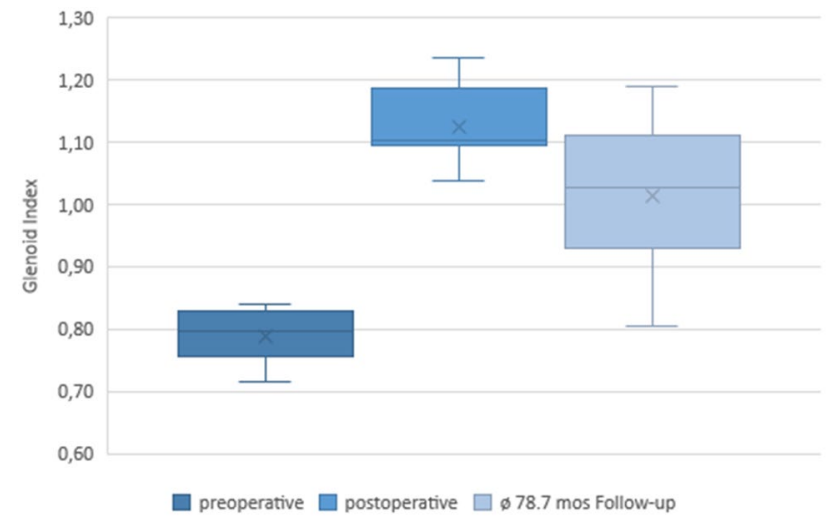

Fig. 4 Glenoid index preoperative, immediately postoperative, and at the final follow-up examination

capsular shift and plication 8 months postoperatively. During revision arthroscopy, coverage of the bone graft with cartilage-like tissue was noted. One patient experienced a traumatic recurrent dislocation. The patient refused a revision surgery due to personal reasons and experienced only mild impairments. The CT scan 68 months postoperatively showed a fracture of the iliac crest bone graft after a downfall on the affected side with resorption of the fragment and recurrence of a glenoid defect. The overall recurrence rate was, therefore, $7.1 \%$ after a follow-up period of 78.7 months.

\section{Discussion}

The most important finding of the present study showed that arthroscopic, autologous iliac crest bone-grafting in recurrent anterior shoulder instability yields satisfying clinical and radiological results after a mid- to long-term follow-up period.

Bone block procedures for treatment of glenoid defects in glenohumeral instability have evolved over a century since the first description by Eden in 1918 and Hybinette in 1932 [15, 22, 25]. Long-term studies with 5-29 years of follow-up of the original procedures showed astonishingly satisfying results. However, relatively high recurrence and arthropathy rates were observed, thus initiating further technical advancement [23, 25, 31-33, 43, 49, 50]. Mid- to long-term evaluations of the present open bone-grafting techniques with a maximum mean follow-up period of 18 years yield good clinical results, low recurrence rates of $0-5 \%$, and instability arthropathy rates of $17-30 \%[4,12,29,40,44$, 47]. However, the postoperative progression of instability arthropathy was not separately evaluated in all studies [46]. Low complication rates were encountered, but iatrogenic damage to the subscapularis muscle including insufficiency, fatty infiltration, and atrophy were identified as disadvantages of the open surgical approach [40, 41, 44].

Facilitating the advantages of minimally invasive surgery and preserving the integrity of the subscapularis 
Fig. $5 \mathrm{CT}$ scan at 68 months postoperative of the patient who experienced a traumatic recurrent dislocation with a fracture of the former iliac crest bone graft
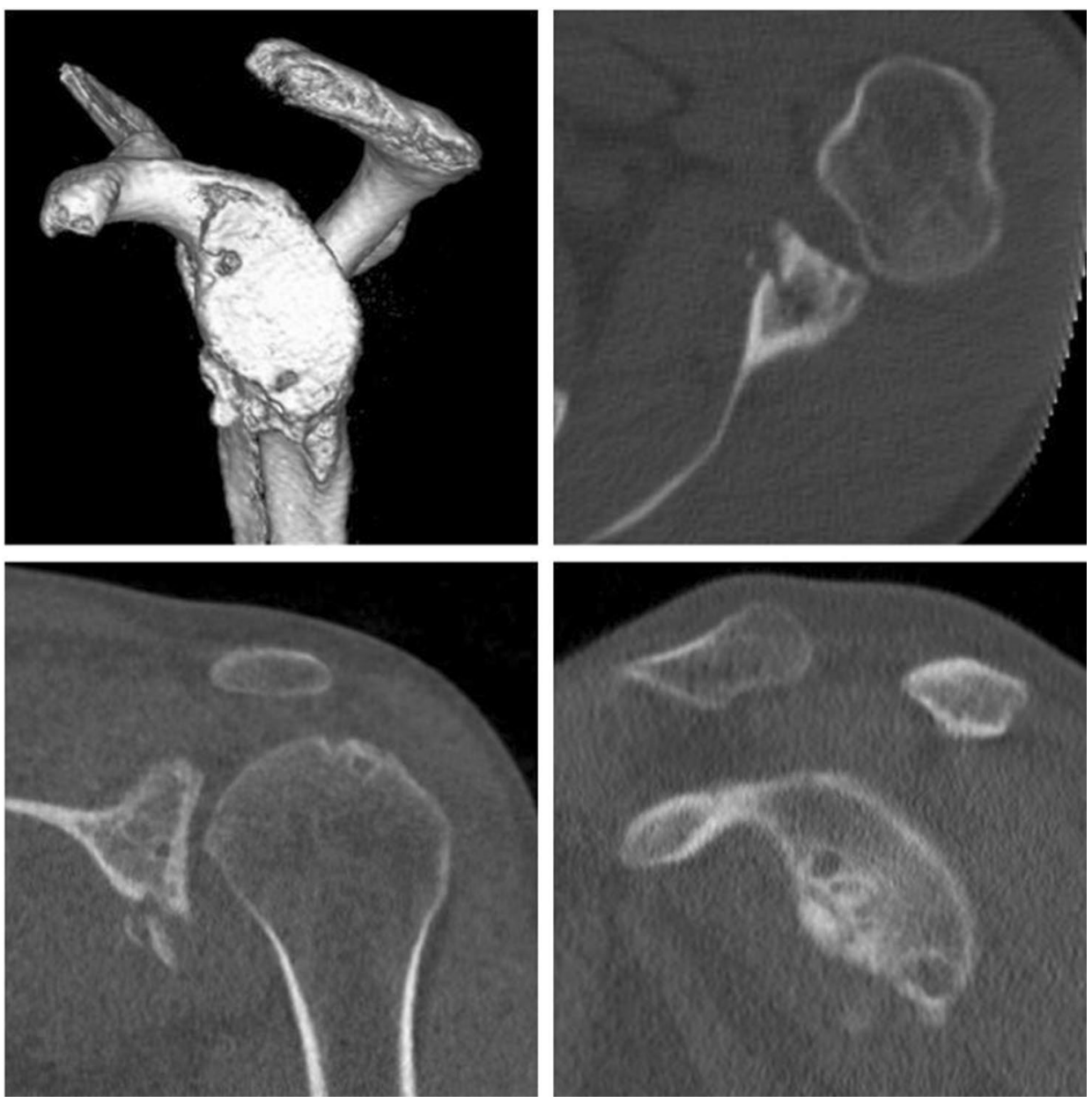

tendon, all-arthroscopic approaches including the implantfree J-bone graft and screw-based fixation methods have been evaluated [2, 5, 24]. Good short-term results were observed without cases of recurrent postoperative anterior instability $[2,24]$. Bockmann et al. recently published the results of a series of 31 patients (follow-up rate of $76 \%$ ) after arthroscopic iliac crest bone-grafting with a followup period of 42 months [5]. In this study, the bone block was fixed using bio-resorbable screws in 22 cases $(71 \%)$ and with titanium screws in 9 patients (29\%). Questionnaire-based re-evaluation showed good outcomes. However, 3 patients (9\%) suffered recurrent dislocations following high-energy traumata 8-17 months postoperatively including a motorbike accident, an epileptic seizure, and a staircase downfall, and required a coracoid transfer as revision surgery. Additional complications included a traumatic fracture around the iliac crest harvesting site $(n=1)$, an empyema of the shoulder $(n=1)$, mechanical irritation surrounding the screw insertion site requiring implant excision $(n=2)$, and an infected superficial haematoma at the pelvis $(n=1)$. However, no radiologic evaluation was conducted at the time of the final follow-up and no clinical examination was performed.

The clinical and radiologic outcomes of our study generally align with the reported short- to mid-term results in the literature. Comparing the results to our previously published short-term results, the clinical shoulder function and radiologic parameters remain relatively stable over time. The mid- to long-term results of the clinical scores, however, seem to be a bit lower than the values reported in the literature for similar surgical procedures. This may be explained by the negative selection of patients who receive this bone-grafting procedure after other treatment options have failed in re-establishing glenohumeral stability. Furthermore, the patients in our study cohort were of relatively high age, suffered multiple preoperative recurrent instability events, a substantial percentage of patients underwent prior surgeries, and showed a preexisting instability arthropathy. After a minimum followup of 5 years, a reconstruction of the anatomic pear-shaped glenoid configuration was observed during radiologic CT-based evaluation. Moroder et al. evaluated the graft remodeling into the anatomic glenoid configuration after 
free bone-grafting using a J-bone graft and observed this process to be completed 1 year postoperatively [28]. The results 60-110 months after surgery support these findings with stagnation of the anatomic glenoid configuration over the mid- to long-term. Progression of instability arthropathy following free bone-grafting procedures requires further investigation. However, in the patient who received a revision arthroscopy with a capsular shift and plication, coverage of the bone graft with cartilage-like tissue was noted. Auffarth et al. investigated the cartilage morphology and histology of iliac crest bone grafts via magnetic resonance imaging (MRI) as well as biopsies, and also observed the grafts to be covered by soft tissue including hyaline-like cartilage and patches of chondrocytes [3, 48]. One of our patients suffered a traumatic recurrent dislocation and a fracture of the bone graft following a postoperative downfall. The recurrence rate of our patient series is, therefore, equal to $7.1 \%$, which compares to the findings by Bockmann et al. No other severe complications were encountered.

Short-term evaluations of the arthroscopic coracoid transfer report recurrence rates ranging from 0 to $6.1 \%$ $[1,6,7,10,13,26,27,51]$. Dumont et al. [14] published mid- to long-term outcomes of 62 patients with a mean follow-up of 76.4 months and observed recurrent subluxations in one patient (1.6\%). A recent randomized comparison [30] of the open J-bone-grafting technique versus the open coracoid transfer according to Latarjet did not find differences in the clinical or radiologic results of the two procedures with exception of a significantly worse range of internal rotation in the Latarjet group and hypaesthesia at the harvesting site at the iliac crest in the free bonegrafting group. However, diverse intra- and postoperative complications have been described in literature following the coracoid transfer including adverse events of high severity such as non-union and/or migration of the graft and hardware problems $[9,10,25]$. A systematic review and meta-analysis of 14 studies comprising 813 patients reported a complication rate of $16.5 \%$ and a revision rate of $5.6 \%$ following the arthroscopic Latarjet procedure [10]. The extra-anatomic approach of the coracoid transfer hinders revision surgery.

Arthroscopic and open approaches of the extra-anatomic Latarjet as well as the anatomic iliac crest bone-grafting procedure are performed for the treatment of substantial anterior glenoid defects. We were able to show that good clinical and radiologic results are achieved by the arthroscopic iliac crest bone-grafting technique after a mid- to long-term follow-up period with the advantages of a minimally invasive and anatomic surgical approach. Limitations of this study are that only a small series of patients of this relatively rare pathology was available for evaluation in our department and no control group was investigated as comparison. Furthermore, no routine preoperative clinical scores were assessed. The surgical procedure is technically challenging, and is performed in specialized centers and by experienced surgeons.

\section{Conclusion}

Arthroscopic reconstruction of anteroinferior glenoid defects using an autologous iliac crest bone-grafting technique yields satisfying clinical and radiologic results after a mid- to long-term follow-up period. Postoperative re-dislocation was experienced in one $(7.1 \%)$ of the patients due to a trauma and an anatomic reconstruction of the pear-shaped glenoid configuration was observed.

Acknowledgements Open Access funding provided by Projekt DEAL. This research was performed at the Center for Musculoskeletal Surgery, Charité-Universitaetsmedizin Berlin.

\section{Compliance with ethical standards}

Conflict of interest Elisabeth Boehm and Marvin Minkus as well as any member of their families have no conflict of interest related to this study. Markus Scheibel is a consultant for Arthrex. Philipp Moroder is a consultant for Mitek.

Funding No funding was received for the conduction of this study.

Ethical approval Approval of the local ethical committee (CharitéUniversitätsmedizin Berlin, Campus Benjamin Franklin) was obtained to perform this study (EA4/168/15).

Open Access This article is licensed under a Creative Commons Attribution 4.0 International License, which permits use, sharing, adaptation, distribution and reproduction in any medium or format, as long as you give appropriate credit to the original author(s) and the source, provide a link to the Creative Commons licence, and indicate if changes were made. The images or other third party material in this article are included in the article's Creative Commons licence, unless indicated otherwise in a credit line to the material. If material is not included in the article's Creative Commons licence and your intended use is not permitted by statutory regulation or exceeds the permitted use, you will need to obtain permission directly from the copyright holder. To view a copy of this licence, visit http://creativecommons.org/licenses/by/4.0/.

\section{References}

1. Ali J, Altintas B, Pulatkan A, Boykin RE, Aksoy DO, Bilsel K (2019) Open versus arthroscopic latarjet procedure for the treatment of chronic anterior glenohumeral instability with glenoid bone loss. Arthroscopy. https://doi.org/10.1016/j.arthr o.2019.09.042

2. Anderl W, Pauzenberger L, Laky B, Kriegleder B, Heuberer PR (2016) Arthroscopic implant-free bone grafting for shoulder instability with glenoid bone loss: clinical and radiological outcome at a minimum 2-year follow-up. Am J Sports Med 44:1137-1145 
3. Auffarth A, Resch H, Matis N, Hudelmaier M, Wirth W, Forstner $\mathrm{R}$ et al (2018) Cartilage morphological and histological findings after reconstruction of the glenoid with an iliac crest bone graft. Am J Sports Med 46:1039-1045

4. Auffarth A, Schauer J, Matis N, Kofler B, Hitzl W, Resch H (2008) The J-bone graft for anatomical glenoid reconstruction in recurrent posttraumatic anterior shoulder dislocation. Am J Sports Med 36:638-647

5. Bockmann B, Venjakob AJ, Reichwein F, Hagenacker M, Nebelung W (2018) Mid-term clinical results of an arthroscopic glenoid rim reconstruction technique for recurrent anterior shoulder instability. Arch Orthop Trauma Surg 138:1557-1562

6. Boileau P, Saliken D, Gendre P, Seeto BL, d'Ollonne T, Gonzalez JF et al (2019) Arthroscopic Latarjet: suture-button fixation is a safe and reliable alternative to screw fixation. Arthroscopy 35:1050-1061

7. Bonnevialle N, Thelu CE, Bouju Y, Vogels J, Agout C, Duriez P et al (2018) Arthroscopic Latarjet procedure with double-button fixation: short-term complications and learning curve analysis. $\mathbf{J}$ Shoulder Elbow Surg 27:e189-e195

8. Bushnell BD, Creighton RA, Herring MM (2008) Bony instability of the shoulder. Arthroscopy 24:1061-1073

9. Butt U, Charalambous CP (2012) Complications associated with open coracoid transfer procedures for shoulder instability. J Shoulder Elbow Surg 21:1110-1119

10. Cerciello S, Corona K, Morris BJ, Santagada DA, Maccauro G (2019) Early outcomes and perioperative complications of the arthroscopic latarjet procedure: systematic review and meta-analysis. Am J Sports Med 47:2232-2241

11. Chuang TY, Adams CR, Burkhart SS (2008) Use of preoperative three-dimensional computed tomography to quantify glenoid bone loss in shoulder instability. Arthroscopy 24:376-382

12. Deml C, Kaiser P, van Leeuwen WF, Zitterl M, Euler SA (2016) The J-shaped bone graft for anatomic glenoid reconstruction: a 10-year clinical follow-up and computed tomography-osteoabsorptiometry study. Am J Sports Med 44:2778-2783

13. do Nascimento AT, Claudio GK, Rocha PB, Zumarraga JP, de Camargo OP (2018) Arthroscopic latarjet technique combined with endobuttons: functional outcomes in 26 cases. Acta Ortop Bras 26:328-331

14. Dumont GD, Fogerty S, Rosso C, Lafosse L (2014) The arthroscopic latarjet procedure for anterior shoulder instability: 5-year minimum follow-up. Am J Sports Med 42:2560-2566

15. Eden (1918) Zur operation der habituellen schulterluxation unter mitteilung eines neuen verfahrens bei abriß am inneren pfannenrande. Dtsch Z Chir 144:269

16. Gerber C, Hersche O, Farron A (1996) Isolated rupture of the subscapularis tendon. J Bone Joint Surg Am 78:1015-1023

17. Gerber C, Krushell RJ (1991) Isolated rupture of the tendon of the subscapularis muscle. Clinical features in 16 cases. J Bone Joint Surg Br 73:389-394

18. Giannakos A, Vezeridis PS, Schwartz DG, Jany R, Lafosse L (2017) All-arthroscopic revision eden-hybinette procedure for failed instability surgery: technique and preliminary results. Arthroscopy 33:39-48

19. Giles JW, Boons HW, Elkinson I, Faber KJ, Ferreira LM, Johnson JA et al (2013) Does the dynamic sling effect of the Latarjet procedure improve shoulder stability? A biomechanical evaluation. J Shoulder Elbow Surg 22:821-827

20. Griffith JF, Antonio GE, Yung PS, Wong EM, Yu AB, Ahuja AT et al (2008) Prevalence, pattern, and spectrum of glenoid bone loss in anterior shoulder dislocation: CT analysis of 218 patients. AJR Am J Roentgenol 190:1247-1254

21. Hertel R, Ballmer FT, Lombert SM, Gerber C (1996) Lag signs in the diagnosis of rotator cuff rupture. J Shoulder Elbow Surg $5: 307-313$
22. Hybinette S (1932) De la transplantation d'un fragment osseux pour remidier aux luxations recidivantes de l'epaule. Constatations et resultats operatoires. Acta Chir Scand 71:411-445

23. Konig DP, Rutt J, Treml O, Hackenbroch MH (1997) Osteoarthritis and recurrences after Putti-Platt and Eden-Hybbinette operations for recurrent dislocation of the shoulder. Int Orthop 21:72-76

24. Kraus N, Amphansap T, Gerhardt C, Scheibel M (2014) Arthroscopic anatomic glenoid reconstruction using an autologous iliac crest bone grafting technique. J Shoulder Elbow Surg 23:1700-1708

25. Ladermann A, Bohm E, Tay E, Scheibel M (2018) Bone-mediated anteroinferior glenohumeral instability: current concepts. Orthopade 47:129-138

26. Meraner D, Smolen D, Sternberg C, Thallinger C, Hahne J, Leuzinger $\mathbf{J}$ (2019) 10 years of arthroscopic latarjet procedure: outcome and complications. Indian J Orthop 53:102-110

27. Metais P, Clavert P, Barth J, Boileau P, Brzoska R, Nourissat $G$ et al (2016) Preliminary clinical outcomes of Latarjet-Patte coracoid transfer by arthroscopy vs. open surgery: prospective multicentre study of 390 cases. Orthop Traumatol Surg Res 102:S271-S276

28. Moroder P, Hirzinger C, Lederer S, Matis N, Hitzl W, Tauber $M$ et al (2012) Restoration of anterior glenoid bone defects in posttraumatic recurrent anterior shoulder instability using the J-bone graft shows anatomic graft remodeling. Am J Sports Med 40:1544-1550

29. Moroder P, Plachel F, Becker J, Schulz E, Abdic S, Haas M et al (2018) Clinical and radiological long-term results after implant-free, autologous, iliac crest bone graft procedure for the treatment of anterior shoulder instability. Am J Sports Med 46:2975-2980

30. Moroder P, Schulz E, Wierer G, Auffarth A, Habermeyer P, Resch H et al (2019) Neer award 2019: Latarjet procedure vs. iliac crest bone graft transfer for treatment of anterior shoulder instability with glenoid bone loss: a prospective randomized trial. J Shoulder Elbow Surg 28:1298-1307

31. Neusel E, Blasius K (1997) Follow-up results 20 years after surgical treatment of habitual ventral shoulder luxation using the Eden-Lange technique. Arch Orthop Trauma Surg 116:217-220

32. Rachbauer F, Ogon M, Wimmer C, Sterzinger W, Huter B (2000) Glenohumeral osteoarthrosis after the Eden-Hybbinette procedure. Clin Orthop Relat Res 373:135-140

33. Rahme H, Wikblad L, Nowak J, Larsson S (2003) Long-term clinical and radiologic results after Eden-Hybbinette operation for anterior instability of the shoulder. J Shoulder Elbow Surg 12:15-19

34. Rowe CR, Zarins B (1981) Recurrent transient subluxation of the shoulder. J Bone Joint Surg Am 63:863-872

35. Samilson RL, Prieto V (1983) Dislocation arthropathy of the shoulder. J Bone Joint Surg Am 65:456-460

36. Scheibel M, Habermeyer P (2008) Subscapularis dysfunction following anterior surgical approaches to the shoulder. J Shoulder Elbow Surg 17:671-683

37. Scheibel M, Kraus N, Diederichs G, Haas NP (2008) Arthroscopic reconstruction of chronic anteroinferior glenoid defect using an autologous tricortical iliac crest bone grafting technique. Arch Orthop Trauma Surg 128:1295-1300

38. Scheibel M, Kraus N, Gerhardt C, Haas NP (2009) Anterior glenoid rim defects of the shoulder. Orthopade 38:41-48, 50-53

39. Scheibel M, Magosch P, Pritsch M, Lichtenberg S, Habermeyer P (2005) The belly-off sign: a new clinical diagnostic sign for subscapularis lesions. Arthroscopy 21:1229-1235

40. Scheibel M, Nikulka C, Dick A, Schroeder RJ, Gerber Popp A, Haas NP (2008) Autogenous bone grafting for chronic 
anteroinferior glenoid defects via a complete subscapularis tenotomy approach. Arch Orthop Trauma Surg 128:1317-1325

41. Scheibel M, Nikulka C, Dick A, Schroeder RJ, Popp AG, Haas NP (2007) Structural integrity and clinical function of the subscapularis musculotendinous unit after arthroscopic and open shoulder stabilization. Am J Sports Med 35:1153-1161

42. Scheibel M, Tsynman A, Magosch P, Schroeder RJ, Habermeyer $P$ (2006) Postoperative subscapularis muscle insufficiency after primary and revision open shoulder stabilization. Am J Sports Med 34:1586-1593

43. Schroder HA, Fristed PB (1985) Recurrent dislocation of the shoulder. The Alvik modification of the Eden-Hybinette operation. Acta Orthop Scand 56:396-399

44. Steffen V, Hertel R (2013) Rim reconstruction with autogenous iliac crest for anterior glenoid deficiency: forty-three instability cases followed for 5-19 years. J Shoulder Elbow Surg 22:550-559

45. Tauber M, Resch H, Forstner R, Raffl M, Schauer J (2004) Reasons for failure after surgical repair of anterior shoulder instability. J Shoulder Elbow Surg 13:279-285

46. Villatte G, Spurr S, Broden C, Martins A, Emery R, Reilly P (2018) The Eden-Hybbinette procedure is one hundred years old!. Int Orthop, A historical view of the concept and its evolutions. https://doi.org/10.1007/s00264-018-3970-3

47. Warner JJ, Gill TJ, O'Hollerhan JD, Pathare N, Millett PJ (2006) Anatomical glenoid reconstruction for recurrent anterior glenohumeral instability with glenoid deficiency using an autogenous tricortical iliac crest bone graft. Am J Sports Med 34:205-212
48. Werner A (2017) Cartilage lesions of the shoulder joint diagnosis and treatment. Obere Extrem 12:134-141

49. Wildner M, Wimmer B, Reichelt A (1994) Osteoarthritis after the Eden-Hybbinette-Lange procedure for anterior dislocation of the shoulder. A 15 year follow up. Int Orthop 18:280-283

50. Wurnig C, Helwig U, Kabon B, Schatz K (1997) Osteoarthrosis after the Max Lange procedure for unstable shoulders. Int Orthop 21:213-216

51. Xu J, Liu H, Lu W, Deng Z, Zhu W, Peng L et al (2020) Modified arthroscopic latarjet procedure: suture-button fixation achieves excellent remodeling at 3-year follow-up. Am J Sports Med 48:39-47

52. Yamamoto N, Muraki T, An KN, Sperling JW, Cofield RH, Itoi E et al (2013) The stabilizing mechanism of the Latarjet procedure: a cadaveric study. J Bone Joint Surg Am 95:1390-1397

53. Yamamoto N, Muraki T, Sperling JW, Steinmann SP, Cofield RH, Itoi E et al (2010) Stabilizing mechanism in bone-grafting of a large glenoid defect. J Bone Joint Surg Am 92:2059-2066

54. Young AA, Maia R, Berhouet J, Walch G (2011) Open Latarjet procedure for management of bone loss in anterior instability of the glenohumeral joint. J Shoulder Elbow Surg 20:S61-69

Publisher's Note Springer Nature remains neutral with regard to jurisdictional claims in published maps and institutional affiliations. 